\title{
LESSONS LEARNED - STARTUP AND TRANSITION TO OPERATIONS AT THE 200 WEST PUMP AND TREAT FACILITY
}

Prepared for the U.S. Department of Energy

Assistant Secretary for Environmental Management

Contractor for the U.S. Department of Energy

under Contract DE-AC06-08RL14788

\section{CHI2MHILL}

Platera Remedration Company

P.O. Box 1600

Richland, Washington 99352 


\section{LESSONS LEARNED - STARTUP AND TRANSITION TO OPERATIONS AT THE 200 WEST PUMP AND TREAT FACILITY}

D. E. FINK

$\mathrm{CH} 2 \mathrm{M}$ Hill

S. P. BURKE

CH2M HILL Plateau Remediation Company
G. G. BERGQUIST

CH2M HILL Plateau Remediation Company

Date Published

September 2012

Prepared for the U.S. Department of Energy

Assistant Secretary for Environmental Management

Contractor for the U.S. Department of Energy

under Contract DE-AC06-08RL14788

\section{CHIMIHILL}

Plateau Remediation Company

P.O. Box 1600

Richland, Washington 99352

By Delores Pinkal at 11:43 am, Oct 03, 2012

Release Approval

Date

Approved for Public Release; Further Dissemination Unlimited 
SGW-53650

Revision 0

\section{TRADEMARK DISCLAIMER}

Reference herein to any specific commercial product, process, or service by tradename, trademark, manufacturer, or otherwise, does not necessarily constitute or imply its endorsement, recommendation, or favoring by the United States Government or any agency thereof or its contractors or subcontractors.

This report has been reproduced from the best avallable copy.

Printed in the United States of America 


\section{Contents}

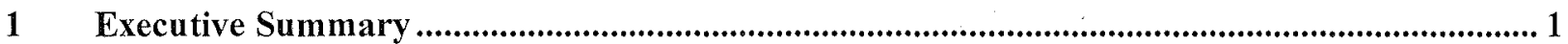

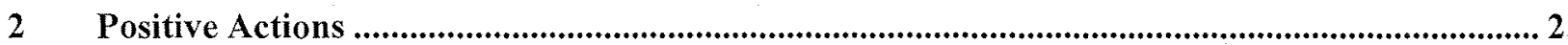

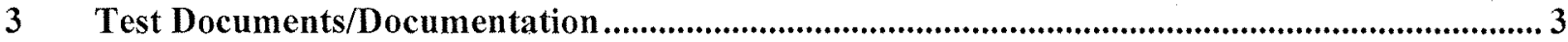

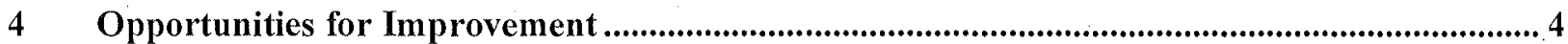




\section{Executive Summary}

This document lists key Lessons Learned from the Startup Team for the 200 West Pump and Treat Facility Project. The Startup Team on this Project was an integrated, multi-discipline team whose scope was Construction Acceptance Testing (CAT), functional Acceptance Testing Procedures (ATP), and procedure development and implementation. Both maintenance and operations procedures were developed. Included in the operations procedures were the process unit operations. In addition, a training and qualification program was also part of the scope.

\section{Positive Actions}

\section{Startup Approach}

The Startup Approach was grounded in a simple integrated and holistic approach utilizing a design process for the correct desired outcome. The design was also grounded in the principles of Human Performance Improvement (HPI) and leveraged the CHPRC Testing and Corrective Action Processes. This approach was selected to present at the DOE Complex-Wide Safety Exposition, June 2011, in Kennewick WA. The approach's most significant desired outcomes were:

- Solid/Grounded Testing Program that leveraged existing CHPRC process and procedures.

- Knowledge and Experience Retention identified key positions that would be staffed and transitioned to the owning client's organization (S\&GRP), i.e., the Technical Authority was transitioned into the position of Plant Engineering Manager, and the Test Coordinator was transitioned into the position of Plant Operations Manager.

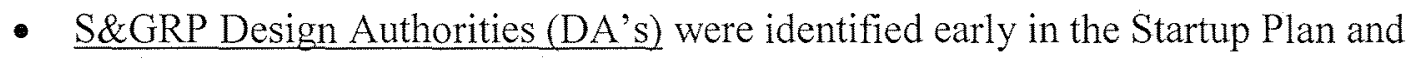
remained responsible for their system's procedures and technical adequacy.

- Operations Supervisors were part of the Startup Team's Test Engineering Staff, where they learned the systems and conducted testing of systems and components.

- Plant Operators were involved in the design process and two senior (27-year plus) Operators were included in the startup staff to assist during construction in the human factors placement of equipment and learning plant capabilities, as well as taking ownership and leadership of the operations procedures development.

- Fulltime Training Professional was embedded with the Startup Team and Operators to develop a solid Training and Qualification Program for the new plant and processes. This approach yielded substantial dividends at the Readiness Evaluation.

- Startup Manager The Startup Manager was matrixed to the Project and retained a directreporting relationship with the Vice President and was a peer to the Project Director. This independence was key in utilizing the CHPRC corrective action process.

- Use of Test Deficiency Reports (TDR's) to clearly and concisely identify issues and track resolution.

- Use of Documented Punch Lists for tracking status through completion.

- $100 \%$ Walk down of drawings by receiving organization after completion by Project. 
- A Robust Testing Program based on the Specifications and the Functional Design Criteria Requirements for the Project.

- The Construction Shift Office ( $\mathrm{CSO}$ ) was staffed by experienced operationš personnel.

\title{
Startup Plan
}

The approach utilized by the Startup Team was to first develop a "Startup Plan" that functioned as a startup-specific sub-project plan. The Startup Plan was an overarching document that covered the "who" scope of the Startup Team. It was used as an effective alignment and communication tool. The Startup Plan was a living, referenceable document in the $200 \mathrm{West}$ Pump and Treat Project Execution Plan (PEP).

The Startup Plan identified the acceptance criteria for the major phases (CAT and ATP) of the Project for the DOE Client. This gave the DOE Client an opportunity to provide its expectations by the defining CAT and ATP.

The Startup Plan defined Roles and Responsibilities for the Startup Team.

The Table of Contents from the "200 West Area Pump and Treat System Startup Plan", SGW-49168, Revision 1, Dated April 2012 is shown below:

\author{
ACRONYMS \\ GLOSSARY \\ 1.0 INTRODUCTION \\ 2.0 OBJECTIVE \\ 3.0 SCOPE \\ 4.0 TEST METHODS \\ 5.0 PRE-OPERATIONS READINESS EVALUATION \\ 6.0 EQUIPMENT AND FACILITIES \\ 7.0 CRITERIA/CONSTRAINTS \\ 8.0 STARTUP ORGANIZATION AND FUNCTIONAL \\ RESPONSIBILITIES \\ 9.0 EXPECTED RESULTS \\ 10.0 TEST SPECIFICATION/TEST PROCEDURE \\ 11.0 SAFETY \\ 12.0 QUALITY ASSURANCE \\ 13.0 SCHEDULE \\ 14.0 REPORTS \\ 15.0 COMMUNICATION PLAN \\ 16.0 TRAINING \\ 17.0 WORK CONTROL \\ 18.0 SOURCES \\ 18.1 Requirements \\ 18.2 References \\ 19.0 APPENDIXES
}


The Startup Plan was used multiple times during in-process reviews, Department of Energy (DOE) Operational Assessments, and Quality Assessment (QA) Surveillances. The document was an extremely valuable resource that communicated our testing program and personnel roles and responsibilities, as well as the sequence of startup of the treatment plant processes to the DOE and the Environmental Protection Agency (EPA).

Recommendation

Recommend the use of this Startup Approach

\section{Test Documents/Documentation}

The fundamental structure of the test documents was redesigned based on the Lessons Learned from the 100 DX and 100 HX Pump \& Treat ATP's.

The Plant Processes and Systems for CAT and ATP were segmented into functional areas:

- Each document was a stand-alone document.

- Each document had Startup, Design Authority, and Project Engineering input and review.

- Each document had clear objectives and steps.

- Each document had electrical and mechanical lineups.

- Each document was grounded in the governing specification and code.

- Each document contains copies of completed tests by vendors.

- Each document contains a boundary illustration of the functional area to be tested.

- Each document was reviewed by a competent Test Engineer and the Test Authority.

- Each document was enveloped in a separate Job Control System (JCS) work package that ensured hazards associated with specific testing activities were evaluated and the appropriate controls were applied. Construction craft and startup testing personnel were involved in the pre-planning walk-downs and workability reviews prior to execution of the work. The Startup Test Coordinator was the Responsible Manager (RM) for the work packages. Changes to the test documents were evaluated for new or changed hazards, and the work packages were revised as necessary.

Recommendation

Propagate the use of this type of test approach and documentation

\section{Opportunities for Improvement}

During the construction and startup of the Facility, several opportunities presented themselves for improvement:

Challenges of Keeping Functional Integrity after Testing Systems and Components There were several instances in which work was performed on functional areas after testing was completed. This caused the potential to void the tested results. For example, pump rotation that was verified during testing was later found to be incorrect following re-work on the systems. 
The Test Engineers ended up having to monitor each of the tested systems for modifications or configuration changes. Additionally, some shared infrastructure systems were required to be placed into service and started being utilized on a daily basis. An example is the chemical systems, which were placed into service to support development of the treatment biology, the compressed air system, and the utility water system.

\section{Recommendation}

A clear turnover strategy needs to be identified and institutionalized early in the project. If a project choses to utilize a partial or rolling turnover of systems and responsibilities they need to be identified early, documented and staffed.

\section{Plastic Debris in System}

Plastic debris left behind from the fabrication process of several fiberglass tanks has resulted in multiple Bio Plant Influent Pump and Fluidized Bed Reactor Pump Strainer shutdowns which required corrective maintenance evolutions to remove the plastic and has delayed progress on the Operational Test Procedure and transition to 24 hour operations. There was indication of plastic during construction flushing activities at Extraction Transfer Building 2 (ETB 2) that was documented in the construction records. Clean water was used during the flushing activities. There were discussions held with the fiberglass tank fabricator about the source of the plastic which were not shared with the Startup Team for further evaluation. Certain tanks have inlet down comers which carry water to near the bottom of the tank. The fiberglass down comers had a thin internal plastic liner which remained in some cases prior to shipment to the Hanford Site for installation. The internal plastic liner is not readily apparent when inspecting a tank for foreign material through an access man way. An opportunity was missed to evaluate other similar tanks and determine a course of action prior to introducing ground water.

Recommendation

Ensure in procurement specifications that all manufacturing debris/foreign material (including forming and lining materials) are cleared from all aspects of the tanks prior to shipment of tanks.

\section{Plastic Pipe Saddles}

Several plastic pipe saddles have failed during Operational Testing of the Facility. The impacts to the Facility have varied from minor to major as was the case for the Utility Water line where a pipe saddle failed and resulted in around 100,000 gallons of water in the Bio building floor and Bio Pad as well as equipment damage to instrumentation and Supervisory Control and Data Acquisition (SCADA) components. The pipe saddles were selected as a means to reduce material costs and labor costs during construction. Several of the remaining plastic pipe saddles have been replaced on the Utility Water System and initial indication are that the saddles were over torqued when installed. A cause analysis is under development by the Soil and Groundwater Remediation Project (S\&GRP).

\section{Recommendation}

Review the piping system to be constructed, especially a piping system using this type of supporting system. Evaluate the potential for saddle failure and potential impacts when choosing 
the saddle material and installation directions. Clearly define all torque value application requirements. Do not allow for interpretation, but generate torque requirements for each application.

\section{Code Compliance}

Additional focus is required when implementing engineering approved specifications from flow down to sub-contractors, review of submittals, and construction verification. Two examples can be cited for lack of compliance to ASME B31.3 code, which resulted in Non-Conformance Reports near construction completion. Examples include the need to install code compliant pressure relieving devices on several chemical pumping skids, and the need for bellows connecting fiberglass tank flanges to attached piping. These two examples resulted in a significant added cost for resolution.

\section{Recommendation}

The next project to utilize this type of piping, and fluid transfer systems, needs to consider how ASME B31.3 code was interpreted by the design organization and what the impacts are on the finished configuration.

\section{Torque Values}

Early on in the Construction Acceptance Testing preparation process the Startup Group identified tightening and torque values as a potential issue.

The project chose not issue specific guidance in some instances, the construction contractors applied their own judgment when setting anchors and installation of pipe flange fasteners. Throughout the Acceptance and Operational Testing Process, several leaks on pipe systems have required repair which in some instances were likely as a results of an improper joint connection.

\section{Recommendation}

Put descriptive verbiage and torque ranges in specification, drawings and inspection plans. This will go toward ensuring sub-contractors will tighten plastic pipe flanges, plastic saddles etc. to the correct value,

\section{Construction Operations/Turnover Responsibilities}

Finally, the turnover of responsibilities from the Construction Shift Office (CSO) to the S\&GRP Operations Organization would have been accomplished more seamlessly if responsibility for work release, work planning, facility lock and tag, etc., could have been transitioned over a period of time.

A better method to maintain positive control by the receiving organization (in this case S\&GRP) and still meet Engineering Projects \& Construction (EPC) objectives could be devised prior the start of the next project-requiring testing.

\section{Recommendation}

A clear turnover strategy needs to be identified and institutionalized early in the project. If a project choses to utilize a partial or rolling turnover of systems and responsibilities they need to be identified early, documented and staffed. 